\title{
Effects of Histidine Supplementation on Amino Acid Metabolism in Rats
}

\author{
Milan HOLEČEK ${ }^{1}$, Melita VODENIČAROVOVÁ ${ }^{1}$ \\ ${ }^{1}$ Department of Physiology, Faculty of Medicine in Hradec Králové, Charles University, Hradec \\ Králové, Czech Republic
}

Received September 4, 2019

Accepted October 22, 2019

Epub Ahead of Print December 19, 2019

\section{Summary}

Histidine (HIS) is investigated for therapy of various disorders and as a nutritional supplement to enhance muscle performance. We examined effects of HIS on amino acid and protein metabolism. Rats consumed HIS in a drinking water at a dose of $0.5 \mathrm{~g} / \mathrm{l}$ (low HIS), $2 \mathrm{~g} / \mathrm{l}$ (high HIS) or $0 \mathrm{~g} / \mathrm{l}$ (control) for 4 weeks. At the end of the study, the animals were euthanized and blood plasma, liver, soleus (SOL), tibialis (TIB), and extensor digitorum longus (EDL) muscles analysed. HIS supplementation increased food intake, body weight and mass and protein contents of the liver and kidneys, but not muscles. In blood plasma there were increases in glucose, urea, and several amino acids, particularly alanine, proline, aspartate, and glutamate and in high HIS group, ammonia was increased. The main findings in the liver were decreased concentrations of methionine, aspartate, and glycine and increased alanine. In muscles of HIS-consuming animals increased alanine and glutamine. In high HIS group (in SOL and TIB) increased chymotrypsin-like activity of proteasome (indicates increased proteolysis); in SOL decreased anserine (beta-alanyl- $\mathrm{N}_{1}$-methylhistidine). We conclude that HIS supplementation increases ammonia production, alanine and glutamine synthesis in muscles, affects turnover of proteins and HIScontaining peptides, and increases requirements for glycine and methionine.

\section{Key words}

Histidine-containing dipeptides - Nutritional supplements • Glutamine • Ammonia

\section{Corresponding author}

M. Holeček, Faculty of Medicine in Hradec Kralove, Charles University, Šimkova 870, 50003 Hradec Kralove, Czech Republic. Fax: +420-49-5210190. E-mail: holecek@lfhk.cuni.cz

\section{Introduction}

Histidine (HIS) is an essential amino acid with unique roles in metabolism, which include proton buffering, metal-ion chelation, anti-oxidative potential, and protection against formation of advanced glycation and lipooxidation end-products (Boldyrev et al. 2013). Besides protein synthesis, HIS can be used for synthesis histamine, 3-methylhistidine, and of various peptides, particularly carnosine and homocarnosine in humans, and anserine and carnosine in rats (Fig. 1).

HIS has been used in therapy of rheumatoid arthritis and anemia of patients with chronic renal failure. At present, HIS and HIS-containing supplements are investigated for therapy of atopic dermatitis, ulcers, inflammatory bowel disease, diabetes, ocular disease, aging, and neurological disorders. HIS is used as a nutritional supplement by people who believe that increased HIS consumption ameliorates feeling of fatigue, improves attentiveness, and enhances muscle performance (Sasahara et al. 2015). Daily HIS supplementation doses range from 1 to $4 \mathrm{~g}$. This represents 2-8 \% of the recommended intake of nitrogen.

Although several studies have demonstrated that HIS intake is safe (Boldyrev et al. 2013), there have been few studies investigating the effects of HIS supplementation on ammonia levels and amino acid distribution in body fluids. Consumption of high HIS amounts may affect transport of other amino acids across cell membranes and impair availability of some amino acids in a number of biochemical pathways and cellular functions. Three molecules of ammonia may arise from the catabolism of one HIS molecule resulting in increased 
ammonia load, which should affect the function of several tissues, particularly the liver and the kidneys. Recent studies show skeletal muscle mitochondrial dysfunction during hyperammonemia (Davuluri et al. 2016).

The main purpose of the present study was to examine the effects of low and high doses of chronic HIS consumption on ammonia and amino acid concentrations in blood plasma, liver, and muscles. Because slow- and fast-twitch muscles have different sensitivities to various signals (Holeček and Mičuda 2017, Holeček and Vodeničarovová 2018, Holeček and Šišpera 2014, Muthný et al. 2008), muscles of different metabolic properties, were examined.

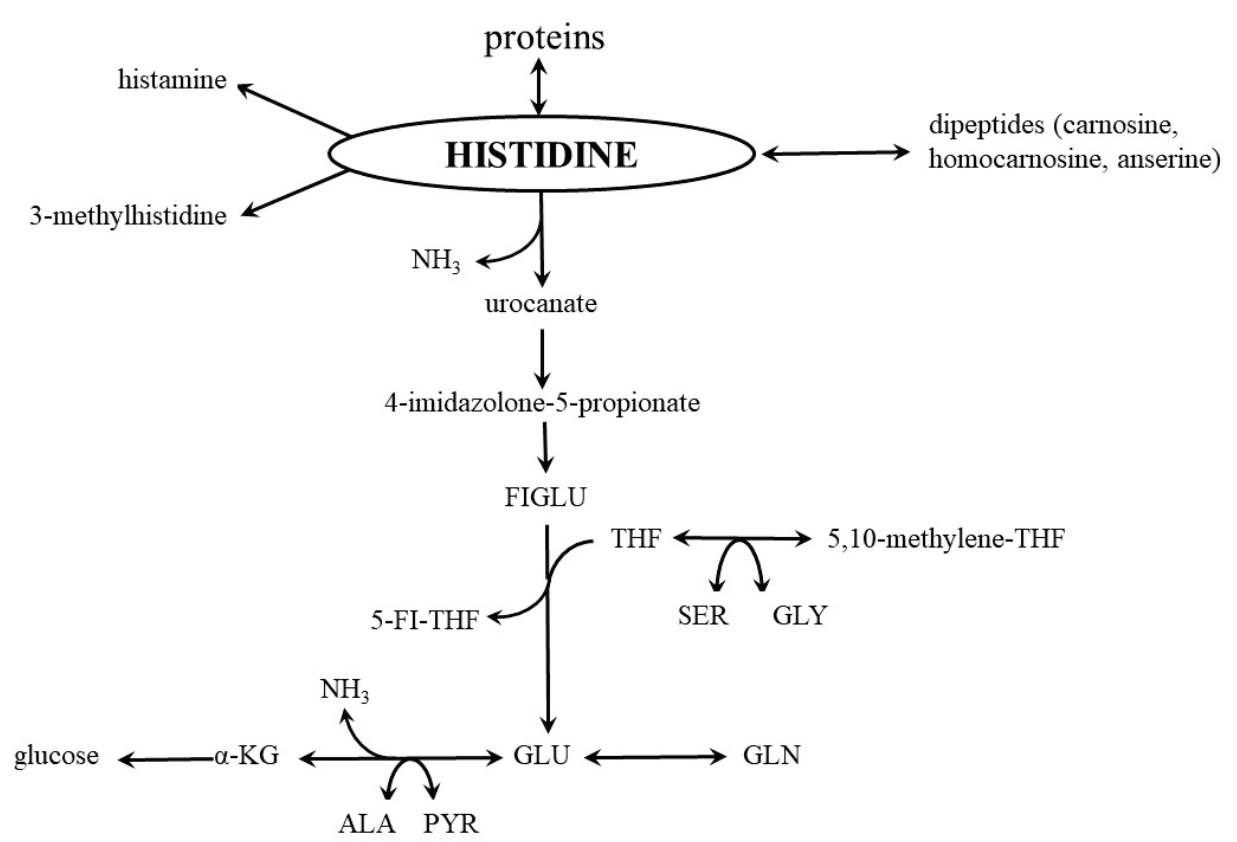

Fig. 1. Overview of the main pathways of HIS metabolism. ALA, alanine; PYR, pyruvate; FIGLU, formiminoglutamate; GLN, glutamine; GLU, glutamic acid; THF, tetrahydrofolate; a-KG, a-ketoglutarate.

\section{Methods}

\section{Animals and materials}

Male Wistar rats (Charles River, Sulzfeld, Germany) weighing approximately $200 \mathrm{~g}$ were housed in standardized cages in quarters with controlled temperature and a 12-hour light-dark cycle. Rats were maintained on an ST-1 (Velas, CR) standard laboratory diet containing (w/w) $24 \%$ nitrogenous compounds, $4 \%$ fat, $70 \%$ carbohydrates and $2 \%$ minerals and vitamins, and were provided drinking water ad libitum. The Animal Care and Use Committee of Charles University, Faculty of Medicine in Hradec Králové (license No. 144879/2011-MZE-17214) approved this study on November 1, 2016 (identification code MSMT33747/2016-4). Animals were treated carefully by animal experts educated and trained in how to manipulate animals to maintain a healthy environment and to reduce distress and minimize potential pain and suffering.

L-Histidine $(99.5 \%)$ was obtained from SigmaAldrich (St. Louis, MO, USA). The chemicals were purchased from Sigma-Aldrich (St. Louis, MO, USA),
Lachema (Brno, CR), Waters (Milford, MA, USA), Biomol (Hamburg, Germany), and Merck (Darmstadt, Germany).

\section{Study design}

Rats were randomly divided into 3 groups ( 7 animals in each) for the intake of drinking water without HIS (controls) or HIS added into the drinking water at a dose of $0.5 \mathrm{~g} / 1$ (low HIS) or $2 \mathrm{~g} / 1$ (high HIS) for 4 weeks. With an average water intake of rat of $100 \mathrm{ml} / \mathrm{kg} / \mathrm{day}$, it means $\sim 50 \mathrm{mg} / \mathrm{kg} /$ day for the low HIS group and $\sim 200 \mathrm{mg} / \mathrm{kg} /$ day for the high HIS group. The doses were selected according to those used to examine the therapeutic effects of HIS on ethanol-induced liver injury and in diabetic mice (Liu et al. 2008, Lee et al. 2005).

The weight and average intake of food and water were measured three times a week. Food intake of a group of 3 or 4 rats was recalculated on a food intake of one animal and expressed in $\mathrm{g} / \mathrm{rat} / \mathrm{day}$ or as a cumulative intake in $g$ per the whole study.

At the end of the study, the overnight fasted 
animals were euthanized in ether anaesthesia by exsanguination from abdominal aorta. Blood was collected in heparinized tubes and immediately centrifuged for $15 \mathrm{~min}$ at $2,500 \times \mathrm{g}$ using a refrigerated centrifuge; blood plasma was transferred into polypropylene tubes using a Pasteur pipette. The liver and tibialis anterior (TIB), soleus (SOL), and extensor digitorum longus (EDL) muscles were quickly removed and weighed. Small pieces $(\sim 0.1 \mathrm{~g})$ of the tissues were frozen in liquid nitrogen.

\section{Blood biochemical markers}

Glucose, urea, creatinine, alanine aminotransferase (ALT), aspartate aminotransferase (AST), triglycerides, and cholesterol were measured using commercial tests (Boehringer, Mannheim, Germany; Elitech, Sées, France, Sigma Chemical, St. Louis, MO, USA, Roche Diagnostics GmbH, Mannheim, Germany, and Lachema, Brno, CR).

\section{Chymotrypsin-like activity (CHTLA) of proteasome}

The CHTLA of the proteasome in the liver and muscles was determined using the fluorogenic substrates Suc-LLVY-MCA (Gomes-Marcondes and Tisdale 2002) as previously described in detail (Holecek and Kovarik 2011). The fluorescence of the samples was measured at the excitation wavelength of $340 \mathrm{~nm}$ and the emission wavelength of $440 \mathrm{~nm}$ (Tecan Infinite M200). A standard curve was established for 7-amino-4-methylcoumarin (AMC), which allowed expression of the enzyme activities in nmol of $\mathrm{AMC} / \mathrm{g}$ protein/hour.
Amino acids, ammonia, and HIS-containing dipeptides

Concentrations of amino acids, ammonia, carnosine, and anserine were determined in supernatants of deproteinized samples of blood plasma, liver, and muscles by high-performance liquid chromatography (HPLC; Aliance 2695, Waters, Milford, MA, USA) after derivatisation with 6-aminoquinolyl-N-hydroxysuccinimidyl carbamate (Waters, Milford, MA, USA) using norleucine as internal standard. The results are expressed as $\mu \mathrm{mol} / \mathrm{l}$ of blood plasma or $\mathrm{nmol} / \mathrm{g}$ of wet tissue.

\section{Statistical analyses}

Analysis of variance (ANOVA) followed by Bonferroni multiple comparison post hoc analysis was used to detect differences between multiple independent groups. NCSS 2001 statistical software (Kaysville, UT, USA) was used for analyses. Results are expressed as means \pm SE. Differences were considered significant at $\mathrm{P}<0.05$

\section{Results}

\section{Blood biochemical markers (Table 1)}

Higher plasma concentrations of glucose and urea were found in both groups of HIS-consuming animals when compared with controls; in high HIS group higher level of ammonia was found. There were no differences in concentrations of ALT, AST, creatinine, triglycerides, and cholesterol between HIS-treated and control animals.

Table 1. Blood biochemical markers.

\begin{tabular}{lccc}
\hline & $\begin{array}{c}\text { Control } \\
(\mathbf{n}=7)\end{array}$ & $\begin{array}{c}\text { Low HIS } \\
(\mathbf{n}=\mathbf{7})\end{array}$ & $\begin{array}{c}\text { High HIS } \\
(\mathbf{n}=7)\end{array}$ \\
\hline Glucose $(\mathrm{mmol} / \mathrm{l})$ & $6.95 \pm 0.28$ & $9.34 \pm 0.48^{*}$ & $9.89 \pm 0.28^{*}$ \\
Ammonia $(\mu \mathrm{mol} / \mathrm{l})$ & $40 \pm 2$ & $40 \pm 4$ & $66 \pm 3^{* \#}$ \\
Urea $(\mathrm{mmol} / \mathrm{l})$ & $6.27 \pm 0.17$ & $8.30 \pm 0.36^{*}$ & $7.74 \pm 0.45^{*}$ \\
Creatinine $(\mu \mathrm{mol} / \mathrm{l})$ & $24.4 \pm 0.9$ & $22.4 \pm 0.9$ & $20.7 \pm 0.9$ \\
ALT $(\mu \mathrm{kat} / \mathrm{l})$ & $0.74 \pm 0.03$ & $0.83 \pm 0.08$ & $0.75 \pm 0.06$ \\
AST $(\mu \mathrm{kat} / \mathrm{l})$ & $1.28 \pm 0.04$ & $1.10 \pm 0.02$ & $1.16 \pm 0.05$ \\
Cholesterol $(\mathrm{mmol} / \mathrm{l})$ & $1.50 \pm 0.08$ & $1.68 \pm 0.13$ & $1.47 \pm 0.08$ \\
HDL cholesterol $(\mathrm{mmol} / \mathrm{l})$ & $1.12 \pm 0.06$ & $1.26 \pm 0.09$ & $1.07 \pm 0.07$ \\
LDL cholesterol $(\mathrm{mmol} / \mathrm{l})$ & $0.25 \pm 0.02$ & $0.30 \pm 0.03$ & $0.23 \pm 0.03$ \\
Triglycerides $(\mathrm{mmol} / \mathrm{l})$ & $0.76 \pm 0.10$ & $1.13 \pm 0.15$ & $1.19 \pm 0.17$ \\
\hline
\end{tabular}

Means $\pm \mathrm{SE}, \mathrm{p}<0.05 .{ }^{*}$ Compared to the control; ${ }^{*}$ high HIS vs. low HIS. 
Ammonia concentration in tissues (Fig. 2)

There was no statistically significant influence of HIS supplementation on ammonia concentration in the liver and muscles.

\section{Body weights and food and water intake (Table 2)}

There were no statistically significant differences among body weights of animals in specific experimental groups on the first day of the experiment. At the time of euthanasia, the body weight of animals of high HIS group was higher when compared with controls.

The values of cumulative food intake, i.e. the total amount of food consumed per animal during the 4 experimental weeks, and average food intake per one animal were higher in HIS-treated animals when compared with controls. There were no differences in water intake between groups. The method used to measure food and water intake did not allow statistical analysis (please see Study design).

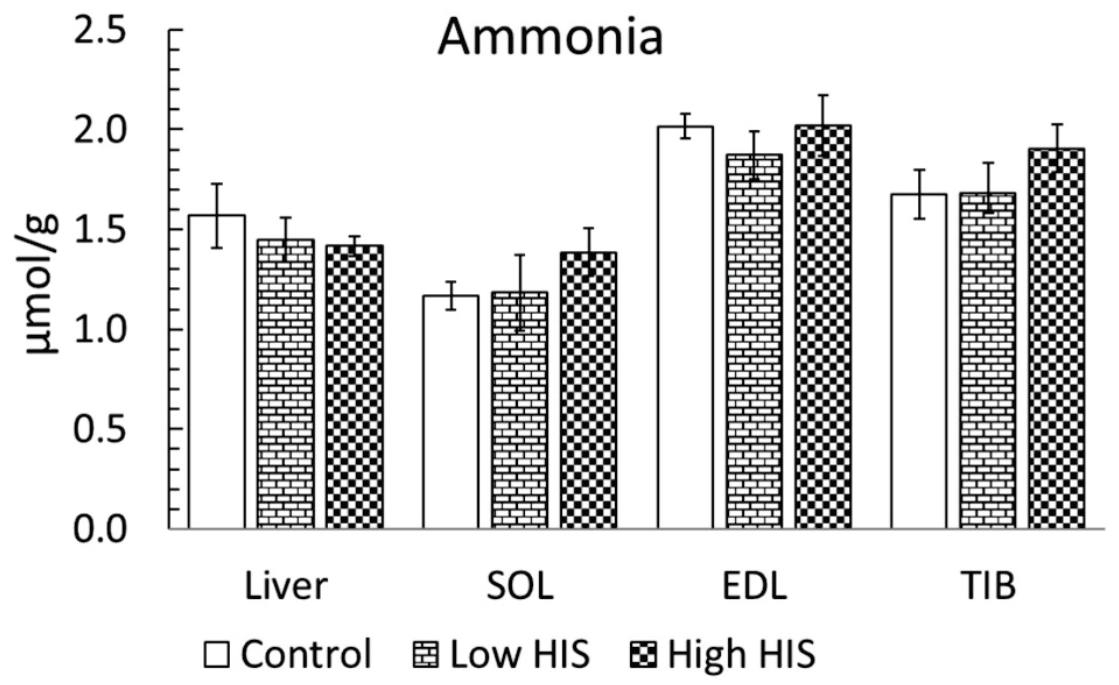

Fig. 2. Ammonia concentration in the liver and muscles. Means $\pm \mathrm{SE}, \mathrm{p}<0.05$.

Table 2. Body weight and food intake.

\begin{tabular}{|c|c|c|c|}
\hline & $\begin{array}{c}\text { Control } \\
(n=7)\end{array}$ & $\begin{array}{c}\text { Low HIS } \\
\quad(n=7)\end{array}$ & $\begin{array}{l}\text { High HIS } \\
\quad(n=7)\end{array}$ \\
\hline \multicolumn{4}{|l|}{ Body weight (g) } \\
\hline Initial & $213 \pm 1$ & $216 \pm 4$ & $212 \pm 3$ \\
\hline Final & $325 \pm 6$ & $340 \pm 7$ & $356 \pm 7 *$ \\
\hline Gain (final-initial) & $112 \pm 6$ & $124 \pm 5$ & $144 \pm 6^{*}$ \\
\hline \multicolumn{4}{|c|}{ Cumulative food intake (g/rat/month) } \\
\hline Cage with 4 rats & 626 & 672 & 717 \\
\hline Cage with 3 rats & 644 & 666 & 691 \\
\hline \multicolumn{4}{|c|}{ Average food intake (g/rat/day) } \\
\hline Cage with 4 rats & 21.6 & 23.2 & 24.7 \\
\hline Cage with 3 rats & 22.2 & 22.8 & 23.8 \\
\hline \multicolumn{4}{|c|}{ Cumulative water intake ( $\mathrm{ml} / \mathrm{rat} / \mathrm{month})$} \\
\hline Cage with 4 rats & 935 & 931 & 954 \\
\hline Cage with 3 rats & 906 & 954 & 915 \\
\hline \multicolumn{4}{|c|}{ Average water intake (ml/rat/day) } \\
\hline Cage with 4 rats & 32.2 & 32.1 & 32.9 \\
\hline Cage with 3 rats & 31.2 & 32.9 & 31.6 \\
\hline
\end{tabular}

Means $\pm \mathrm{SE}, \mathrm{p}<0.05$. ${ }^{*}$ Compared to the control; ${ }^{*}$ high HIS vs. low HIS. Statistical analysis of the effect of HIS supplementation on food and water intake was not performed (since a group of 3 or 4 animals was used to obtain average values). 
Weights and protein contents of the liver, muscles, and the kidneys (Table 3)

At the time of euthanasia, the liver mass and hepatic protein content were significantly greater in HIS consuming animals when compared with controls. There were no statistically significant differences in the weight and protein content of muscles among experimental groups. However, the relative values (per $\mathrm{kg}$ of body weight) of the weight of EDL and protein content of TIB were significantly lower when compared with controls.
The absolute values of the weight and protein content of the kidneys were higher in HIS-consuming animals when compared with controls.

\section{CHTLA of proteasome (Fig. 3)}

Significant increase in CHTLA activity was found in SOL (in both HIS-supplemented groups) and in TIB (in high HIS group). The effect of HIS supplementation on CHTLA in the liver and EDL was insignificant.

Table 3. Weight and protein content of tissues.

\begin{tabular}{|c|c|c|c|}
\hline & $\begin{array}{c}\text { Control } \\
(n=7)\end{array}$ & $\begin{array}{c}\text { Low HIS } \\
\quad(n=7)\end{array}$ & $\begin{array}{l}\text { High HIS } \\
\quad(n=7)\end{array}$ \\
\hline LIVER weight (g) & $8.31 \pm 0.20$ & $9.88 \pm 0.33^{*}$ & $10.27 \pm 0.41^{*}$ \\
\hline$-g / k g b . w$. & $25.6 \pm 0.4$ & $29.1 \pm 0.9 *$ & $28.8 \pm 0.9^{*}$ \\
\hline Protein (g) & $1.54 \pm 0.05$ & $1.89 \pm 0.06^{*}$ & $1.95 \pm 0.07 *$ \\
\hline$-g / k g / b . w$ & $4.74 \pm 0.09$ & $5.56 \pm 0.16^{*}$ & $5.50 \pm 0.22 *$ \\
\hline SOL weight (mg) & $149 \pm 4$ & $149 \pm 10$ & $156 \pm 3$ \\
\hline$-m g / k g ~ b . w$. & $460 \pm 18$ & $436 \pm 25$ & $439 \pm 13$ \\
\hline Protein - $m g$ & $21.3 \pm 1.4$ & $22.5 \pm 1.1$ & $22.3 \pm 1.2$ \\
\hline$-m g / k g / b . w$ & $65.5 \pm 4.5$ & $66.1 \pm 2.7$ & $62.9 \pm 3.9$ \\
\hline EDL weight (mg) & $167 \pm 3$ & $170 \pm 6$ & $171 \pm 3$ \\
\hline$-m g / k g / b . w$ & $515 \pm 6$ & $501 \pm 11$ & $481 \pm 9^{*}$ \\
\hline Protein (mg) & $28 \pm 1$ & $28 \pm 1$ & $28 \pm 1$ \\
\hline$-m g / k g / b . w$ & $85 \pm 2$ & $81 \pm 1$ & $78 \pm 3$ \\
\hline TIB weight (mg) & $678 \pm 18$ & $682 \pm 18$ & $697 \pm 20$ \\
\hline$-g / k g / b . w$ & $2.09 \pm 0.06$ & $2.01 \pm 0.04$ & $1.96 \pm 0.05$ \\
\hline Protein (mg) & $106 \pm 2$ & $104 \pm 1$ & $103 \pm 4$ \\
\hline$-m g / k g / b . w$ & $327 \pm 7$ & $307 \pm 5$ & $289 \pm 12 *$ \\
\hline KIDNEY weight (mg) & $0.99 \pm 0.03$ & $1.14 \pm 0.03^{*}$ & $1.18 \pm 0.04^{*}$ \\
\hline$-m g / k g / b . w$ & $3.06 \pm 0.08$ & $3.34 \pm 0.08$ & $3.31 \pm 0.11$ \\
\hline Protein (mg) & $131 \pm 4$ & $146 \pm 6$ & $152 \pm 4^{*}$ \\
\hline$-m g / k g / b . w$ & $404 \pm 9$ & $431 \pm 20$ & $427 \pm 12$ \\
\hline
\end{tabular}

Means $\pm \mathrm{SE}, \mathrm{p}<0.05$. ${ }^{*}$ Compared to the control; " high HIS vs. low HIS.

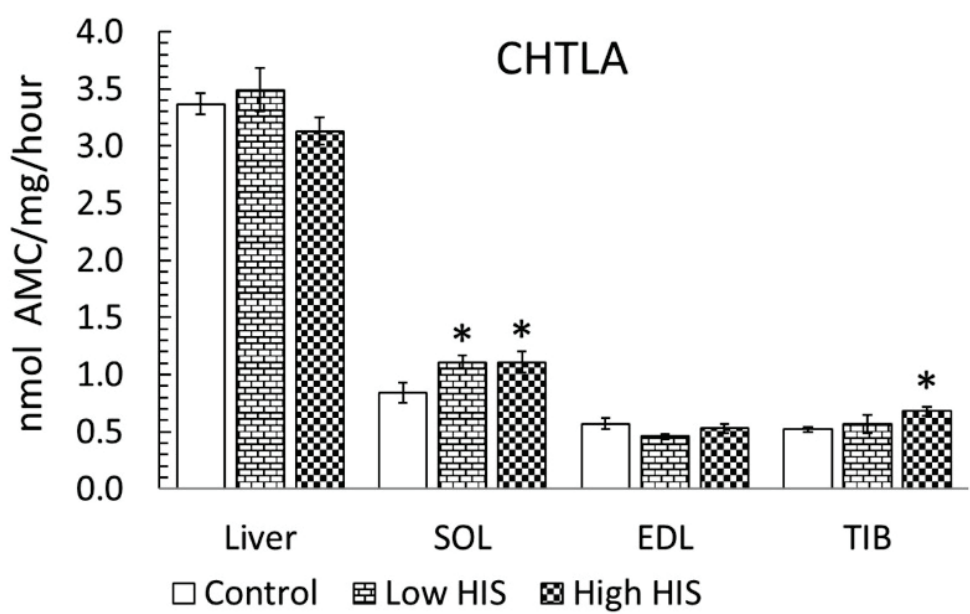

Fig. 3. CHTLA of proteasome in the liver and muscles. Means $\pm \mathrm{SE}, \mathrm{p}<0.05$. * Compared to the control. 
Amino acid concentrations in blood plasma (Table 4)

We found higher concentrations of HIS, alanine, aspartate, glutamate, and proline in both groups of HISsupplemented animals when compared with controls. Furthermore, in high HIS group we found higher concentrations of leucine, phenylalanine, arginine, and tyrosine.

Amino acid concentrations in the liver (Table 5)

Higher concentrations of HIS and alanine and lower concentrations of methionine and aspartate we found in both HIS-supplemented groups when compared with controls. In addition, significantly lower concentration of glycine we found in high HIS group and higher concentration of serine we found in low HIS group.

Amino acid concentrations in muscles (Tables 6-8)

HIS concentration increased in all muscle types in both groups of HIS treated animals. In all muscle types of high HIS group were found markedly higher concentrations of alanine and glutamine when compared with controls. Significantly higher concentrations of alanine and glutamine were found also in EDL and TIB of low HIS group. There were several differences in the effect of HIS supplementation on concentrations of other amino acids in individual muscles.

Table 4. Amino acid concentrations in blood plasma ( $\mu \mathrm{mol} / \mathrm{l})$.

\begin{tabular}{|c|c|c|c|}
\hline & $\begin{array}{c}\text { Control } \\
(n=7)\end{array}$ & $\begin{array}{c}\text { Low HIS } \\
(n=7)\end{array}$ & $\begin{array}{l}\text { High HIS } \\
\quad(n=7)\end{array}$ \\
\hline \multicolumn{4}{|l|}{$E A A$} \\
\hline Histidine & $50 \pm 1$ & $60 \pm 2 *$ & $61 \pm 2 *$ \\
\hline Isoleucine & $112 \pm 2$ & $111 \pm 5$ & $117 \pm 7$ \\
\hline Leucine & $155 \pm 3$ & $159 \pm 5$ & $180 \pm 10^{*}$ \\
\hline Lysine & $306 \pm 15$ & $318 \pm 13$ & $358 \pm 19$ \\
\hline Methionine & $41 \pm 1$ & $43 \pm 2$ & $46 \pm 2$ \\
\hline Phenylalanine & $59 \pm 1$ & $62 \pm 1$ & $70 \pm 3^{* \#}$ \\
\hline Threonine & $205 \pm 4$ & $228 \pm 13$ & $231 \pm 5$ \\
\hline Valine & $202 \pm 3$ & $207 \pm 9$ & $227 \pm 11$ \\
\hline$\Sigma E A A$ & $1,131 \pm 20$ & $1,188 \pm 44$ & $1,293 \pm 48^{*}$ \\
\hline \multicolumn{4}{|l|}{$N E A A$} \\
\hline Alanine & $256 \pm 7$ & $326 \pm 19^{*}$ & $411 \pm 26^{* \#}$ \\
\hline Beta-alanine & $9 \pm 0$ & $9 \pm 0$ & $10 \pm 0$ \\
\hline Arginine & $120 \pm 3$ & $125 \pm 5$ & $147 \pm 5^{* \#}$ \\
\hline Asparagine & $49 \pm 1$ & $57 \pm 2$ & $62 \pm 4$ \\
\hline Aspartate & $7 \pm 0$ & $9 \pm 1^{*}$ & $10 \pm 1 *$ \\
\hline Citrulline & $66 \pm 3$ & $74 \pm 3$ & $65 \pm 2$ \\
\hline Cysteine & $117 \pm 4$ & $106 \pm 4$ & $105 \pm 6$ \\
\hline Glutamate & $74 \pm 3$ & $86 \pm 3^{*}$ & $97 \pm 6^{*}$ \\
\hline Glutamine & $533 \pm 7$ & $589 \pm 14$ & $585 \pm 24$ \\
\hline Glycine & $313 \pm 13$ & $294 \pm 13$ & $295 \pm 11$ \\
\hline Ornithine & $38 \pm 1$ & $47 \pm 4$ & $48 \pm 3$ \\
\hline Proline & $113 \pm 2$ & $135 \pm 5^{*}$ & $142 \pm 4^{*}$ \\
\hline Serine & $185 \pm 8$ & $195 \pm 8$ & $209 \pm 9$ \\
\hline Taurine & $175 \pm 13$ & $175 \pm 15$ & $176 \pm 19$ \\
\hline Tyrosine & $82 \pm 3$ & $95 \pm 5$ & $100 \pm 4^{*}$ \\
\hline$\Sigma N E A A$ & $2,137 \pm 23$ & $2,323 \pm 51$ & $2,462 \pm 92 *$ \\
\hline$\Sigma A A$ & $3,268 \pm 33$ & $3,510 \pm 86$ & $3,755 \pm 137 *$ \\
\hline
\end{tabular}

Means $\pm \mathrm{SE}, \mathrm{p}<0.05 .{ }^{*}$ Compared to the control; ${ }^{*}$ high HIS vs. low HIS. EAA, essential amino acids; NEAA, non-essential amino acids; $A A$, amino acids. 
Table 5. Amino acid concentrations in the liver (nmol/g).

\begin{tabular}{|c|c|c|c|}
\hline & $\begin{array}{c}\text { Control } \\
(n=7)\end{array}$ & $\begin{array}{c}\text { Low HIS } \\
\quad(n=7)\end{array}$ & $\begin{array}{l}\text { High HIS } \\
\quad(n=7)\end{array}$ \\
\hline \multicolumn{4}{|l|}{$E A A$} \\
\hline Histidine & $613 \pm 18$ & $691 \pm 13 *$ & $649 \pm 24$ \\
\hline Isoleucine & $186 \pm 9$ & $190 \pm 9$ & $185 \pm 5$ \\
\hline Leucine & $297 \pm 16$ & $306 \pm 14$ & $308 \pm 7$ \\
\hline Lysine & $746 \pm 99$ & $731 \pm 45$ & $586 \pm 37$ \\
\hline Methionine & $49 \pm 3$ & $32 \pm 3^{*}$ & $34 \pm 2 *$ \\
\hline Phenylalanine & $103 \pm 4$ & $111 \pm 5$ & $108 \pm 5$ \\
\hline Valine & $316 \pm 14$ & $320 \pm 13$ & $318 \pm 10$ \\
\hline$\Sigma E A A$ & $2,310 \pm 152$ & $2,381 \pm 89$ & $2,187 \pm 61$ \\
\hline \multicolumn{4}{|l|}{$N E A A$} \\
\hline Alanine & $1,259 \pm 58$ & $2,607 \pm 316^{*}$ & $2,655 \pm 298^{*}$ \\
\hline Beta-alanine & $147 \pm 11$ & $161 \pm 16$ & $140 \pm 10$ \\
\hline Arginine & $41 \pm 10$ & $44 \pm 11$ & $28 \pm 3$ \\
\hline Asparagine & $77 \pm 5$ & $87 \pm 5$ & $80 \pm 4$ \\
\hline Aspartate & $1,186 \pm 59$ & $941 \pm 84^{*}$ & $950 \pm 57^{*}$ \\
\hline Glutamate & $1,607 \pm 134$ & $1,371 \pm 89$ & $1,315 \pm 73$ \\
\hline Glutamine & $5,594 \pm 105$ & $5,886 \pm 264$ & $5,954 \pm 407$ \\
\hline Glycine & $3,316 \pm 142$ & $3,094 \pm 151$ & $2,530 \pm 87^{* \#}$ \\
\hline Ornithine & $306 \pm 14$ & $341 \pm 23$ & $300 \pm 16$ \\
\hline Proline & $148 \pm 10$ & $179 \pm 9$ & $166 \pm 11$ \\
\hline Serine & $363 \pm 30$ & $477 \pm 37^{*}$ & $390 \pm 18$ \\
\hline Taurine & $5,167 \pm 875$ & $3,858 \pm 96$ & $5,245 \pm 814$ \\
\hline Tyrosine & $114 \pm 8$ & $112 \pm 5$ & $111 \pm 3$ \\
\hline$\Sigma N E A A$ & $20,852 \pm 1,311$ & $20,563 \pm 379$ & $21,254 \pm 1,259$ \\
\hline$\Sigma A A$ & $23,162 \pm 1,435$ & $22,945 \pm 388$ & $23,441 \pm 1,296$ \\
\hline
\end{tabular}

Means $\pm \mathrm{SE}, \mathrm{p}<0.05 .{ }^{*}$ Compared to the control; ${ }^{*}$ high HIS vs. low HIS. EAA, essential amino acids; NEAA, non-essential amino acids; $A A$, amino acids.

HIS-containing dipeptides in muscles (Fig. 4)

Statistically significant decrease in anserine concentration was found in SOL in high HIS group. The decrease in anserine in TIB was on a margin of our level of significance. The effect of HIS supplementation on carnosine content was insignificant.

\section{Discussion}

To our knowledge, very few studies have been conducted on the effects of HIS supplementation on amino acid distribution among tissues. The data reported here indicate that HIS administered chronically in drinking water increases food intake and weights of the liver and the kidneys and alters amino acid concentrations in the blood and tissues. The remarkable effects were increased concentrations of alanine and glutamine in blood plasma and muscles and decreased concentrations of glycine and methionine in the liver.

\section{Effect of HIS supplementation on food intake}

Several studies have demonstrated an anorectic effect of HIS-enriched diet (Kasoaka et al. 2004, Goto et al. 2007). In contrast, our study demonstrated increased food intake in rats drinking HIS-enriched water.

The explanation for our surprising result can be based on recent findings, which indicate that sensing of amino acid depletion in hypothalamus plays a role in pathogenesis of anorectic response to essential amino acid-devoid diet (Anthony and Gietzen 2013). Because HIS shares the cellular transporters with other amino 
Table 6. Amino acid concentrations in SOL (nmol/g).

\begin{tabular}{|c|c|c|c|}
\hline SOL & $\begin{array}{c}\text { Control } \\
\qquad(n=7)\end{array}$ & $\begin{array}{c}\text { Low HIS } \\
\quad(n=7)\end{array}$ & $\begin{array}{l}\text { High HIS } \\
\qquad(n=7)\end{array}$ \\
\hline \multicolumn{4}{|l|}{$E A A$} \\
\hline Histidine & $356 \pm 17$ & $426 \pm 42$ & $484 \pm 17 *$ \\
\hline Isoleucine & $92 \pm 3$ & $98 \pm 4$ & $102 \pm 3$ \\
\hline Leucine & $130 \pm 4$ & $143 \pm 7$ & $157 \pm 5^{*}$ \\
\hline Lysine & $740 \pm 64$ & $759 \pm 47$ & $746 \pm 43$ \\
\hline Methionine & $47 \pm 2$ & $47 \pm 2$ & $52 \pm 2$ \\
\hline Phenylalanine & $60 \pm 2$ & $67 \pm 3$ & $72 \pm 2 *$ \\
\hline Threonine & $391 \pm 16$ & $463 \pm 27^{*}$ & $436 \pm 17$ \\
\hline Valine & $170 \pm 5$ & $183 \pm 6$ & $205 \pm 7 *^{\#}$ \\
\hline$\Sigma E A A$ & $1,594 \pm 80$ & $1,724 \pm 57$ & $1,818 \pm 51 *$ \\
\hline \multicolumn{4}{|l|}{$N E A A$} \\
\hline Alanine & $1,844 \pm 100$ & $1,945 \pm 99$ & $2,335 \pm 118^{* \#}$ \\
\hline Asparagine & $480 \pm 21$ & $513 \pm 32$ & $509 \pm 37$ \\
\hline Aspartate & $2,348 \pm 183$ & $2,301 \pm 215$ & $2,537 \pm 177$ \\
\hline Glutamate & $3,706 \pm 134$ & $3,852 \pm 226$ & $3,546 \pm 100$ \\
\hline Glutamine & $5,017 \pm 225$ & $5,886 \pm 178$ & $6,128 \pm 286^{*}$ \\
\hline Glycine & $1,906 \pm 47$ & $1,990 \pm 125$ & $1,654 \pm 85^{*}$ \\
\hline Ornithine & $50 \pm 3$ & $56 \pm 3$ & $51 \pm 1$ \\
\hline Proline & $235 \pm 5$ & $268 \pm 12$ & $275 \pm 16$ \\
\hline Serine & $1,381 \pm 68$ & $1,576 \pm 122$ & $1,501 \pm 132$ \\
\hline Taurine & $21,061 \pm 413$ & $21,325 \pm 980$ & $20,027 \pm 383$ \\
\hline Tyrosine & $97 \pm 5$ & $119 \pm 6^{*}$ & $120 \pm 3 *$ \\
\hline$\Sigma N E A A$ & $38,803 \pm 860$ & $40,596 \pm 1,701$ & $39,377 \pm 1,042$ \\
\hline$\Sigma A A$ & $40,397 \pm 879$ & $42,320 \pm 1,717$ & $41,195 \pm 1,066$ \\
\hline
\end{tabular}

Means $\pm \mathrm{SE}, \mathrm{p}<0.05$. ${ }^{*}$ Compared to the control; ${ }^{*}$ high HIS vs. low HIS. EAA, essential amino acids; NEAA, non-essential amino acids; $A A$, amino acids.

acids, the effect of competition may decrease transport of several amino acids to the brain and cause anorexia in subjects on HIS-enriched diet. We hypothesize that the possibility to attenuate imbalance in amino acid concentration by feeding behaviour is the basis of neurohumoral changes in the brain promoting the food intake of rats drinking HIS-enriched water in our study. This adaptation is not possible if there is HIS-enriched food, as is the case in studies declaring the anorectic effect of HIS supplementation.

Effect of HIS supplementation on body weight and weight and protein content of tissues

In line with increased food intake, significant increase in body weight was recorded in HIS-consuming animals. Remarkably increased weights and protein content of the liver and the kidneys. However, the increase in absolute weight and protein content of the muscles was insignificant and the relative values (per $\mathrm{kg}$ of body weight) even dropped in SOL and TIB.

We assume that increased mass of the liver and the kidneys is due to higher nitrogen load by food and HIS content in water. Higher values of CHTLA of proteasome in SOL and TIB muscles indicate that increased breakdown of myofibrillar proteins might play a role in impaired gain of muscle mass.

Effect on HIS supplementation on amino acid concentrations

Since concentrations of several amino acids decreased and the rats were killed after overnight fasting, we do not believe that a slightly increased food intake 
Table 7. Amino acid concentrations in EDL (nmol/g).

\begin{tabular}{|c|c|c|c|}
\hline$E D L$ & $\begin{array}{c}\text { Control } \\
\qquad(n=7)\end{array}$ & $\begin{array}{c}\text { Low HIS } \\
\quad(n=7)\end{array}$ & $\begin{array}{l}\text { High HIS } \\
\quad(n=7)\end{array}$ \\
\hline \multicolumn{4}{|l|}{$E A A$} \\
\hline Histidine & $118 \pm 4$ & $172 \pm 10 *$ & $187 \pm 10^{*}$ \\
\hline Isoleucine & $118 \pm 2$ & $121 \pm 7$ & $135 \pm 6$ \\
\hline Leucine & $150 \pm 4$ & $160 \pm 8$ & $186 \pm 9^{* \#}$ \\
\hline Lysine & $313 \pm 15$ & $402 \pm 28^{*}$ & $466 \pm 21 *$ \\
\hline Methionine & $51 \pm 1$ & $54 \pm 4$ & $61 \pm 2 *$ \\
\hline Phenylalanine & $67 \pm 1$ & $76 \pm 3$ & $85 \pm 4^{*}$ \\
\hline Threonine & $334 \pm 19$ & $411 \pm 26$ & $425 \pm 23 *$ \\
\hline Valine & $208 \pm 4$ & $225 \pm 12$ & $260 \pm 11^{* \#}$ \\
\hline$\Sigma E A A$ & $1,358 \pm 31$ & $1,620 \pm 83^{*}$ & $1,806 \pm 58^{*}$ \\
\hline \multicolumn{4}{|l|}{$N E A A$} \\
\hline Alanine & $1,627 \pm 61$ & $1,853 \pm 61^{*}$ & $1,996 \pm 55^{*}$ \\
\hline Asparagine & $159 \pm 6$ & $198 \pm 13^{*}$ & $221 \pm 8^{*}$ \\
\hline Aspartate & $326 \pm 14$ & $353 \pm 19$ & $319 \pm 13$ \\
\hline Glutamate & $1,371 \pm 121$ & $1,224 \pm 76$ & $1,146 \pm 104$ \\
\hline Glutamine & $2,731 \pm 153$ & $3,628 \pm 230^{*}$ & $3,636 \pm 197^{*}$ \\
\hline Glycine & $2,113 \pm 64$ & $2,567 \pm 129 *$ & $2,411 \pm 159$ \\
\hline Ornithine & $28 \pm 4$ & $32 \pm 2$ & $35 \pm 2$ \\
\hline Proline & $211 \pm 5$ & $244 \pm 7^{*}$ & $270 \pm 11^{*}$ \\
\hline Serine & $521 \pm 29$ & $636 \pm 32 *$ & $678 \pm 32 *$ \\
\hline Taurine & $15,193 \pm 375$ & $16,257 \pm 485$ & $15,989 \pm 308$ \\
\hline Tyrosine & $114 \pm 3$ & $140 \pm 9^{*}$ & $144 \pm 8^{*}$ \\
\hline$\Sigma N E A A$ & $24,747 \pm 681$ & $27,539 \pm 562 *$ & $27,220 \pm 617^{*}$ \\
\hline$\Sigma A A$ & $26,105 \pm 695$ & $29,159 \pm 590$ & $29,026 \pm 666^{*}$ \\
\hline
\end{tabular}

Means $\pm \mathrm{SE}, \mathrm{p}<0.05 .{ }^{*}$ Compared to the control; " high HIS vs. low HIS. EAA, essential amino acids; NEAA, non-essential amino acids; $A A$, amino acids.

observed in HIS-consuming rats would have a significant effect on alterations in amino acid levels. We suppose that the main role has increased flux of HIS through the HIS degradation pathway in the liver and HIS deamination to urocanate by histidase in the skin (Fig. 1).

The most of ammonia produced during HIS catabolism to glutamate and by glutamate dehydrogenase reaction in the liver is undoubtedly detoxified to urea, as indicated by increased urea concentration in the blood. Increased $\alpha$-ketoglutarate production by glutamate dehydrogenase reaction may activate gluconeogenesis resulting in observed increase in glycaemia, as suggested by Brosnan (2000) who demonstrated that the bulk of the carbon skeleton appearing due to increased hepatic amino acid catabolism is converted to glucose.

The findings of increased concentration of glutamate and ammonia in the blood indicate that some amounts of glutamate are released to the systemic circulation and that some ammonia, probably cutaneous origin, escapes detoxification to urea. Under these conditions alternative ammonia detoxification pathway is activated; by synthesis of glutamine from glutamate in a process catalyzed by glutamine synthetase in skeletal muscle as shown by several articles reporting the stimulatory effect of ammonia on glutamine synthesis (Clemmesen et al. 2000, Girard and Butterworth 1992, Holecek et al. 2000, Holecek et al. 2011). The suggestion is supported by increased glutamine concentration in all examined muscles of HIS-supplemented animals, by finding that the most of the glutamate released by the liver is removed by skeletal muscle (Cynober 2018, Klin et al. 2010), and that most of the administered nitrogen label of ${ }^{15} \mathrm{~N}$ glutamate appeared in the arterial alanine and 
Table 8. Amino acid concentrations in TIB ( $\mathrm{nmol} / \mathrm{g})$.

\begin{tabular}{|c|c|c|c|}
\hline$T I B$ & $\begin{array}{c}\text { Control } \\
(n=7)\end{array}$ & $\begin{array}{c}\text { Low HIS } \\
\quad(n=7)\end{array}$ & $\begin{array}{l}\text { High HIS } \\
\quad(n=7)\end{array}$ \\
\hline \multicolumn{4}{|l|}{$E A A$} \\
\hline Histidine & $128 \pm 3$ & $168 \pm 8^{*}$ & $178 \pm 10 *$ \\
\hline Isoleucine & $121 \pm 3$ & $120 \pm 8$ & $128 \pm 4$ \\
\hline Leucine & $152 \pm 4$ & $160 \pm 9$ & $176 \pm 6^{*}$ \\
\hline Lysine & $391 \pm 31$ & $494 \pm 40$ & $562 \pm 29 *$ \\
\hline Methionine & $57 \pm 2$ & $55 \pm 4$ & $61 \pm 2$ \\
\hline Phenylalanine & $76 \pm 3$ & $82 \pm 5$ & $87 \pm 2 *$ \\
\hline Threonine & $334 \pm 11$ & $404 \pm 21^{*}$ & $401 \pm 19^{*}$ \\
\hline Valine & $216 \pm 4$ & $222 \pm 12$ & $250 \pm 9 *$ \\
\hline$\Sigma E A A$ & $1,141 \pm 45$ & $1,300 \pm 73$ & $1,442 \pm 31^{*}$ \\
\hline \multicolumn{4}{|l|}{$N E A A$} \\
\hline Alanine & $1,390 \pm 57$ & $1,627 \pm 37$ & $1,693 \pm 69 *$ \\
\hline Asparagine & $469 \pm 19$ & $553 \pm 29$ & $561 \pm 26^{*}$ \\
\hline Aspartate & $319 \pm 17$ & $306 \pm 17$ & $314 \pm 11$ \\
\hline Glutamate & $1,397 \pm 110$ & $1,131 \pm 90$ & $1,248 \pm 119$ \\
\hline Glutamine & $2,297 \pm 82$ & $2,718 \pm 129 *$ & $2,791 \pm 119^{*}$ \\
\hline Glycine & $2,070 \pm 95$ & $2,389 \pm 174$ & $2,061 \pm 130$ \\
\hline Ornithine & $29 \pm 1$ & $37 \pm 2^{*}$ & $36 \pm 2^{*}$ \\
\hline Proline & $430 \pm 13$ & $392 \pm 18$ & $484 \pm 21^{\#}$ \\
\hline Serine & $469 \pm 19$ & $553 \pm 29$ & $561 \pm 26^{*}$ \\
\hline Taurine & $15,028 \pm 375$ & $14,880 \pm 775$ & $15,649 \pm 502$ \\
\hline Tyrosine & $128 \pm 5$ & $149 \pm 11$ & $149 \pm 5$ \\
\hline$\Sigma N E A A$ & $24,176 \pm 470$ & $24,900 \pm 801$ & $25,700 \pm 781$ \\
\hline$\Sigma A A$ & $25,318 \pm 457$ & $26,201 \pm 863$ & $27,142 \pm 799$ \\
\hline
\end{tabular}

Means $\pm \mathrm{SE}, \mathrm{p}<0.05$. ${ }^{*}$ Compared to the control; ${ }^{*}$ high HIS vs. low HIS. EAA, essential amino acids; NEAA, non-essential amino acids; $A A$, amino acids.
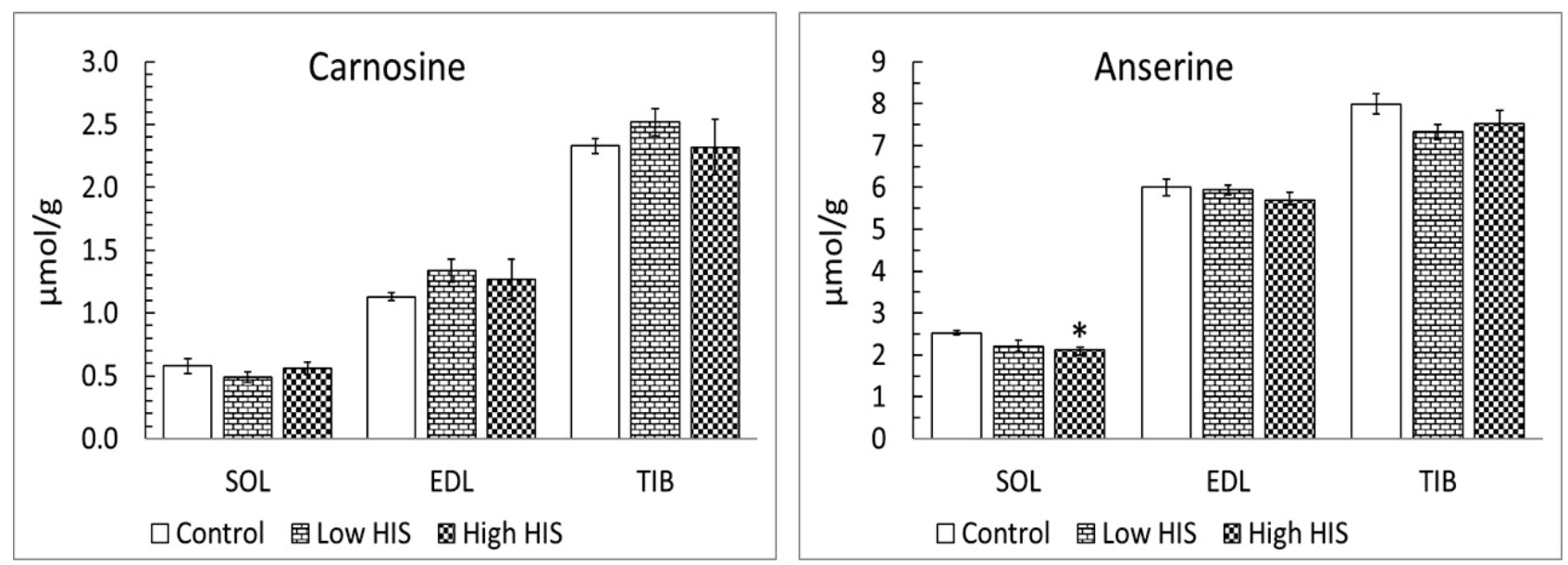

Fig. 4. Carnosine and anserine concentrations in muscles. Means $\pm \mathrm{SE}, \mathrm{p}<0.05$. ${ }^{*}$ Compared to the control. 
glutamine (Johnson et al. 1988). A role in high levels of alanine in the liver may play not only increased alanine release from muscles, but also impaired hepatic conversion of alanine to glutamate by alanine aminotransferase due to high glutamate concentration.

Our results revealed decreased hepatic concentrations of glycine in high HIS group and methionine in both HIS-supplemented groups. We assume that the cause of decreased glycine concentration is enhanced consumption of tetrahydrofolate (THF), which is required for conversion of serine to glycine (Fig. 1). The hypothesis is supported by findings of Meléndez-Hevia et al. (2009) who proven that THFdependent synthesis of glycine from serine accounts for more than $85 \%$ of the total. Increased THF consumption might play a role also in observed decrease in methionine concentration. It has been shown that methionine cycle plays a role in availability of folate (Fell and Steele 1983), experiments using isolated rat hepatocytes showed that HIS oxidation increased two- to fourfold by the addition of methionine, S-adenosylmethionine, homocysteine, or S-adenosylhomocysteine (Billings et al. 1981).

Effect of HIS supplementation on anserine and carnosine contents in muscles

HIS is a precursor of several dipeptides, such as carnosine (beta-alanyl-L-histidine) and anserine (betaalanyl- $\mathrm{N}_{1}$-methylhistidine), which are found almost exclusively in skeletal muscle. Carnosine in humans, both carnosine and anserine are present in rats. The peptides play significant role in proton buffering and it is believed that an increase in their intramuscular concentration improves high-intensity exercise performance and reduces muscle fatigue (Suzuki et al. 2006).

Unfortunately, the reports of HIS supplementation on content of HIS-containing dipeptides in skeletal muscle are not entirely conclusive. In rats fed a HIS-excess diet decreased body and gastrocnemius muscle weight, increased carnosine and anserine content in muscles, and increased urinary excretion of 3-methylhistidine (Tamaki et al. 1977). Unlike the findings in animals, HIS supplementation did not induce an increase in carnosine content in human muscles (Blancquaert et al. 2017). The present study showed a decrease in anserine content in SOL in HIS consuming animals, which was not found in EDL and TIB muscles.

\section{Differences between red and white muscles}

In HIS-consuming animals, significantly lower weights or protein contents were found in EDL and TIB muscles, but not in SOL. The finding is in line with our previous reports demonstrating enhanced susceptibility of white muscles to various signals when compared with red ones (Holecek and Micuda 2017, Holecek and Vodenicarovova 2018, Holecek and Sispera 2014, Muthny et al. 2008). A role in a different response might play a higher protein turnover in red muscles indicated by higher amino acid content and higher CHTLA in SOL when compared with EDL and TIB.

In accordance with the anaerobic energy delivery in fast-twitch muscles and the supposed role of HIS-containing dipeptides as an efficient intracellular $\mathrm{pH}$ buffer is our finding of higher anserine content in EDL and TIB muscles when compared with SOL.

\section{Conclusions}

We conclude that HIS administered chronically in drinking water increases food intake, body weight, and weights of the liver and the kidneys, but not of muscles. The remarkable changes in amino acid concentrations include increased concentrations of alanine, glutamate, and glutamine in blood plasma and muscles, and decreased concentrations of glycine and methionine in the liver.

We assume that the cause of hyperphagia is adaptive response aiming to attenuate imbalance in amino acid concentrations due to HIS excess in drinking water. The main role in pathogenesis of altered amino acid concentrations has increased flux of HIS through the HIS degradation pathway leading to enhanced production of ammonia and glutamate, which are in muscles used for synthesis of alanine and glutamine. We suggest that HIS supplementation is a special way of glutamine supplementation, which has a number of benefits, particularly on function of the gut and immune system (Newsholme and Hardy 1997). The cause of decreased concentrations of methionine and glycine in the liver might be THF depletion. The results indicate that chronic intake of excessive amounts of HIS increases requirements for glycine, which may be, therefore, classified as conditionally essential amino acid.

\section{Conflict of Interest}

There is no conflict of interest. 


\section{Acknowledgements}

This study was supported by the programme PROGRES Q40/02. The authors wish to thank R. Fingrová, K. Šildbergerová, and D. Ježková for their technical assistance.

\section{Abbreviations}

ALT, alanine aminotransferase; AST, aspartate aminotransferase; BCAA, branched-chain amino acids (valine, leucine, and isoleucine); CHTLA, chymotrypsinlike activity; EDL, extensor digitorum longus muscle; FIGLU, formiminoglutamate; GLN, glutamine; GLU, glutamic acid; HIS, histidine; HPLC, high-performance liquid chromatography; SOL, soleus muscle; THF, tetrahydrofolate; TIB, tibialis anterior muscle; $\alpha-\mathrm{KG}, \alpha$-ketoglutarate.

\section{References}

ANTHONY TG, GIETZEN DW: Detection of amino acid deprivation in the central nervous system. Curr Opin Clin Nutr Metab Care 16: 96-101, 2013. https://doi.org/10.1097/MCO.0b013e32835b618b

BILLINGS RE, NOKER PE, TEPHLY TR: The role of methionine in regulating folate-dependent reactions in isolated rat hepatocytes. Arch Biochem Biophys 208: 108-120, 1981. https://doi.org/10.1016/0003-9861(81)90129-6

BLANCQUAERT L, EVERAERT I, MISSINNE M, BAGUET A, STEGEN S, VOLKAERT A, PETROVIC M, VERVAET C, ACHTEN E, DE MAEYER M, DE HENAUW S, DERAVE W: Effects of histidine and $\beta$-alanine supplementation on human muscle carnosine storage. Med Sci Sports Exerc 49: 602-609, 2017. https://doi.org/10.1249/MSS.0000000000001213

BOLDYREV AA, ALDINI G, DERAVE W: Physiology and pathophysiology of carnosine. Physiol Rev 93: 1803-1845, 2013. https://doi.org/10.1152/physrev.00039.2012

BROSNAN JT: Glutamate at the interface between amino acid and carbohydrate metabolism. J Nutr 130: 988S-990S, 2000. https://doi.org/10.1093/jn/130.4.988S

CLEMMESEN JO, KONDRUP J, OTT P: Splanchnic and leg exchange of amino acids and ammonia in acute liver failure. Gastroenterology 118: 1131-1139, 2000. https://doi.org/10.1016/S0016-5085(00)70366-0

CYNOBER L: Metabolism of dietary glutamate in adults. Ann Nutr Metab 73: Suppl 5: 5-14, 2018. https://doi.org/10.1159/000494776

DAVULURI G, ALLAWY A, THAPALIYA S, RENNISON JH, SINGH D, KUMAR A, SANDLERS Y, VAN WAGONER DR, FLASK CA, HOPPEL C, KASUMOV T, DASARATHY S: Hyperammonaemiainduced skeletal muscle mitochondrial dysfunction results in cataplerosis and oxidative stress. J Physiol 594: 7341-7360, 2016. https://doi.org/10.1113/JP272796

FELL D, STEELE RD: Effect of methionine on in vivo histidine metabolism in rats. J Nutr 113: 860-866, 1983. https://doi.org/10.1093/jn/113.4.860

GIRARD G, BUTTERWORTH RF: Effect of portacaval anastomosis on glutamine synthetase activities in liver, brain, and skeletal muscle. Dig Dis Sci 37: 1121-1126, 1992. https://doi.org/10.1007/BF01300297

GOMES-MARCONDES MC, TISDALE MJ: Induction of protein catabolism and the ubiquitin-proteasome pathway by mild oxidative stress. Cancer Lett 180: 69-74, 2002. https://doi.org/10.1016/S0304-3835(02)00006-X

GOTO K, KASAOKA S, TAKIZAWA M, OGAWA M, TSUCHIYA T, NAKAJIMA S: Bitter taste and blood glucose are not involved in the suppressive effect of dietary histidine on food intake. Neurosci Lett 420: 106-109, 2007. https://doi.org/10.1016/j.neulet.2007.03.074

HOLECEK M, SPRONGL L, TICHÝ M: Effect of hyperammonemia on leucine and protein metabolism in rats. Metabolism 49: 1330-1334, 2000. https://doi.org/10.1053/meta.2000.9531

HOLECEK M, KANDAR R, SISPERA L, KOVARIK M: Acute hyperammonemia activates branched-chain amino acid catabolism and decreases their extracellular concentrations: different sensitivity of red and white muscle. Amino Acids 40: 575-584, 2011. https://doi.org/10.1007/s00726-010-0679-z

HOLECEK M, KOVARIK M: Alterations in protein metabolism and amino acid concentrations in rats fed by a highprotein (casein-enriched) diet - effect of starvation. Food Chem Toxicol 49: 3336-3342, 2011. https://doi.org/10.1016/j.fct.2011.09.016 
HOLECEK M, SISPERA L: Glutamine deficiency in extracellular fluid exerts adverse effects on protein and amino acid metabolism in skeletal muscle of healthy, laparotomized, and septic rats. Amino Acids 46: 1377-1384, 2014. https://doi.org/10.1007/s00726-014-1701-7

HOLEČEK M, MIČUDA S: Amino acid concentrations and protein metabolism of two types of rat skeletal muscle in postprandial state and after brief starvation. Physiol Res 66: 959-967, 2017.

HOLEČEK M, VODENIČAROVOVÁ M: Effects of beta-hydroxy-beta-methylbutyrate in partially hepatectomized rats. Physiol Res 67: 741-751, 2018. https://doi.org/10.33549/physiolres.933861

JOHNSON AW, BERRINGTON JM, WALKER I, MANNING A, LOSOWSKY MS: Measurement of the transfer of the nitrogen moiety of intestinal lumen glutamic acid in man after oral ingestion of 1-[15N]glutamic acid. Clin Sci (Lond) 75: 499-502, 1988. https://doi.org/10.1042/cs0750499

MELÉNDEZ-HEVIA E, DE PAZ-LUGO P, CORNISH-BOWDEN A, CÁRDENAS ML: A weak link in metabolism: the metabolic capacity for glycine biosynthesis does not satisfy the need for collagen synthesis. J Biosci 34 : 853-872, 2009. https://doi.org/10.1007/s12038-009-0100-9

KASAOKA S, TSUBOYAMA-KASAOKA N, KAWAHARA Y, INOUE S, TSUJI M, EZAKI O, KATO H, TSUCHIYA T, OKUDA H, NAKAJIMA S: Histidine supplementation suppresses food intake and fat accumulation in rats. Nutrition 20: 991-996, 2004. https://doi.org/10.1016/j.nut.2004.08.006

KLIN Y, ZLOTNIK A, BOYKO M, OHAYON S, SHAPIRA Y, TEICHBERG V: Distribution of radiolabeled l-glutamate and d-aspartate from blood into peripheral tissues in naive rats: significance for brain neuroprotection. Biochem Biophys Res Commun 399: 694-698, 2010. https://doi.org/10.1016/j.bbrc.2010.07.144

LEE YT, HSU CC, LIN MH, LIU KS, YIN MC: Histidine and carnosine delay diabetic deterioration in mice and protect human low density lipoprotein against oxidation and glycation. Eur J Pharmacol 513: 145-150, 2005. https://doi.org/10.1016/j.ejphar.2005.02.010

LIU WH, LIU TC, YIN MC: Beneficial effects of histidine and carnosine on ethanol-induced chronic liver injury. Food Chem Toxicol 46: 1503-1509, 2008. https://doi.org/10.1016/j.fct.2007.12.013

MUTHNY T, KOVARIK M, SISPERA L, TILSER I, HOLECEK M: Protein metabolism in slow- and fast-twitch skeletal muscle during turpentine-induced inflammation. Int J Exp Pathol 89: 64-71, 2008. https://doi.org/10.1111/j.1365-2613.2007.00553.x

NEWSHOLME E, HARDY G: Supplementation of diets with nutritional pharmaceuticals. Nutrition 13: 837-839, 1997. https://doi.org/10.1016/S0899-9007(97)00253-0

SASAHARA I, FUJIMURA N, NOZAWA Y, FURUHATA Y, SATO H: The effect of histidine on mental fatigue and cognitive performance in subjects with high fatigue and sleep disruption scores. Physiol Behav 147: 238-244, 2015. https://doi.org/10.1016/j.physbeh.2015.04.042

SUZUKI Y, NAKAO T, MAEMURA H, SATO M, KAMAHARA K, MORIMATSU F, TAKAMATSU K: Carnosine and anserine ingestion enhances contribution of nonbicarbonate buffering. Med Sci Sports Exerc 38: 334-338, 2006.

TAMAKI N, TSUNEMORI F, WAKABAYASHI M, HAMA T: Effect of histidine-free and -excess diets on anserine and carnosine contents in rat gastrocnemius muscle. J Nutr Sci Vitaminol (Tokyo) 23: 331-340, 1977. https://doi.org/10.3177/jnsv.23.331 